\title{
Teaching Electron Microscopy; A Variety of Options for a Diverse Range of Students
}

\author{
Stuart McKernan ${ }^{1}$. \\ 1. Retired. \\ * Corresponding author: stuart.mckernan@gmail.com
}

In any electron microscopy lab there are several different objectives that underpin the teaching of those using the instruments. From the point of view of the lab manager, the students must be sufficiently well educated on the actual use of the instrument that downtime and equipment failures are minimized. From the advisor's point of view, the student should get up to speed and producing useful (and not erroneous of artefactual) results as soon as possible, maybe also with the least amount of scheduling of his time. Thirdly, from the point of view of a potential employer (either in the industrial or academic world) the student should understand the broad range of electron microscopy techniques and not just the single focus of their $\mathrm{PhD}$ thesis. The student themselves may also need to learn different techniques to find information not available to them at their current level of familiarity with electron microscopy. It can be supposed that these differing points of view do not necessarily lead to the same learning curriculum for a student.

Over the last fifty years in electron microscopy, the instruments have changed considerably; both in ease of use and in numbers available. In the early days, the focus of microscopy was on understanding the instrument and the images it produced and developing new techniques that would reveal more information about the sample. Teaching was then a more individual learning situation: you learned from the microscopist who developed the instrument or technique. As researchers moved on to new institutions, it was possible to follow the lineage of microscopy groups back to there original seats of learning.

As any field matures the focus moves away from instrument and technique development, and towards applications to particular problems. The microscopy becomes a means to an end rather than an end in itself. The teaching process might place less emphasis on how the microscope works and the theory involved in the image production and more on which techniques may be used to provide the information necessary from the sample in question, and how the data may be best interpreted. In small labs with a focus on a specific range of problems, this might ne easily accomplished in a small group setting without any resort to an extended microscopy course. In larger labs, or labs with a variety of areas of interest, this process rapidly becomes very inefficient.

There are several possible ways to address this situation, but one of the most common avenues is to put together a TEM 101 course so that all users become familiar with the basics of the instrument and are introduced to most of the techniques they will use. It does not take many students for this to become more time-effective than individual instruction. Over the years many such courses have been developed, but one of the most popular resources for such courses is "Transmission Electron Microscopy: A Textbook for Materials Science" by Williams and Carter [1]. One reason for its popularity is identified by John Spence in the foreword to the second edition: 'Like all the best textbooks, this one was distilled from lecture notes, debugged over many years and generations of students.' That process has resulted in a very broad ranging textbook with chapters that can easily form the basis of individual, self-contained 
lectures. There are other, similar textbooks available that perform the same function, but this is one that has stood the test of time.

Having been involved in a small way in that initial debugging process, and later taking the material in the textbook and putting together some introduction to electron microscopy courses at the Characterization Facility at the University of Minnesota, I have learned a little about different educational approaches to the teaching of STEM and TEM at various levels. The same basic course has been used for graduate students, undergraduates and also as part of a capstone semester for students of the Dakota County Technical College. That audience covers a great range including; actively engaged students keen to learn as much as possible about microscopy, students who need to be able to use the microscope for a small part of their research, students who need to add another technique to their c.v. before moving on, and technical students looking for training to become a microscope operator in industry. In all these cases the lectures have been supplemented with practical sessions on the microscope, either individually or in small work groups.

Comparisons of several iterations of this course - from its initial inception as a way of managing the user training in the facility to a for-credit course that rewarded the students for the time they devoted to the subject - will be discussed. The particular circumstances of the number of microscopes, the availability of staff members, the number of students, and the time available are all factors that will affect the suitability of our solution, and their effects on the training will be addressed.

Two data point that bracket this work highlight the benefit of using such a comprehensive textbook as the basis for an introductory course. The first was a researcher who instructed his student to learn the TEM and get some images of the graphene layers he "knew" he had grown. The researcher had to be told that the fringes on the images he had just shown in a departmental talk were astigmatism and not lattice images of graphene layers. That event sparked the need for a more thorough grounding of all the TEM users rather than showing them how to use the instrument without breaking it. The second data point is the number of former students I meet at microscopy meetings who are still successfully using microscopy in their careers [2].

References:

[1] D B Williams and C B Carter., "Transmission Electron Microscopy: A Textbook for Materials Science" Springer (2009).

[2] The author gratefully acknowledges decades of support and encouragement from Prof. C. B. Carter. 